Vesna G. Polovina*

https://doi.org/10.18485/analiff.2018.30.1.16

Filološki fakultet

$81^{\prime} 42: 316.774$

Univerzitet u Beogradu

316.774:81'27

Melina M. Nikolić

Originalni naučni rad

Primljen: 24.06.2018.

Fakultet za strane jezike

Prihvaćen: 12.09.2018.

Alfa BK univerzitet, Beograd

\title{
NARUŠAVANJE ODNOSA MOĆI U KONFRONTACIONOM INTERVJUU
}

Medijski intervju predstavlja specifičan vid institucionalnog diskursa koji Herritage definiše kao „functionally specialized form of social interaction produced for an overhearing audience and restricted by institutionalized conventions" (Herritage, 1985:112). U pomenute konvencije spadaju odnosi moći koji su strogo regulisani i ograničeni već samom formom intervjua u kojem voditelj ima svu moć u diskursu. Ta moć je najizraženija u takozvanom konfrontacionom intervjuu. Konfrontacioni intervju je savremeni istraživački intervju koji se od klasičnog intervjua razlikuje po načinu vođenja razgovora, vrsti i načinu formulacije pitanja, kao i načinu održavanja odnosa moći. U ovom radu su istraženi primeri narušavanja tih normativiziranih odnosa moći iz perspektive kritičke analize diskursa koja se prvenstveno bavi proučavanjem jezika i njegove upotrebe u socio-kulturnom kontekstu u funkciji uspostavljanja, održavanja i narušavanja odnosa moći među učesnicima u diskursu. Analizirana su jezička sredstva i diskurzivne strategije kojima intervjisana osoba pokušava da preuzme kontrolu u razgovoru u kojem njena normativna uloga nije uloga moćnog sagovornika. Rezultati istraživanja ukazuju na činjenicu da ni u institucionalizovanom diskursu odnosi moći nisu strogo oktroisani i da može doći do narušavanja unapred utvrđenih diskurzivnih pravila.

Ključne reči: konfrontacioni intervju, institucionalni diskurs, kritička analiza diskursa, odnosi moći

\section{Kritička analiza diskursa i konfrontacioni diskurs}

Polazeći od pretpostavke da diskurs konstituiše društvo, ali i da je on sam društveno uslovljen, kritička analiza diskursa posmatra diskurs isključivo u okviru društvenog i kulturnog konteksta i iz kritičke perspektive proučava

*_polovinav@fil.bg.ac.rs 
jezik i njegovu upotrebu u funkciji uspostavljanja, održavanja i narušavanja odnosa moći među učesnicima u diskursu. Predstavnici ove lingvističke discipline smatraju da je institucionalni diskurs izvor govora moći, a posebnu pažnju posvetili su medijskom diskursu. Analiziran je veliki broj medijskih formi, a naročiti fokus stavljen je na intervju. S obzirom na činjenicu da kritička analiza diskursa pokušava da razotkrije "skrivena" značenja u diskursu, proučavanje ove medijske forme zavređuje posebnu pažnju jer mediji predstavljaju pogodno tlo za manipulisanje javnim mnjenjem.

U medijskom diskursu uopšte, pa i u intervjuima, zastupljene su raznovrsne oblasti i teme iz društvenog života: ekonomske, političke, umetničke, sportske itd. Možda najdominantniji u savremenim medijima je politički diskurs, koji je prepoznatljiv po ,proračunatom dizajnu“ (Fairclough i Wodak, 1997: 259), ali i po uticaju koji ima na javnost, pa se stoga možda najviše pažnje u kritičkoj analizi diskursa posvećuje njemu. Ispoljava se kroz političke debate, govore, reklame u predizbornim kampanjama i sl., u štampanim i elektronskim medijima. Jedan od oblika ispoljavanja je ,konfrontacioni““ intervju, koji pretenduje da upravo razotkriva skrivena značenja, potencijalnu manipulaciju od strane sagovornika, najčešće političara, kroz specifičnu orijentaciju intervjua.

Konfrontacioni intervju ${ }^{1}$ je zapravo moderan oblik klasičnog intervjua kojim su pitanja direktnija, a izbegavanje odgovora otežano. Definicije intervjua i određenje uloge sagovornika u takvom diskursu koje možemo naći kod autora koji su se intervjuom bavili iz lingvističke perspektive nepotpune su za potrebe ovakvog istraživanja (Wolfson 1976, Kress \&Fowler 1979, Schegloff 1992, Fairclough 1995, Hutchby \&Wooffitt 1998, Clayman \& Heritage 2002, Heritage\&Clayman 2010, i mnogi drugi). Nikolić (2017), razmatrajući različite definicije medijskih intervjua zaključuje da je klasični intervju ,komunikativni događaj koji se odvija $\mathrm{u}$ formi dijaloga kroz pitanja i odgovore, između predstavnika medija, tj. profesionalnog novinara i osobe relevantne za aktuelne događaje, čija je svrha informisanje javnosti. Odnosi moći se ogledaju u neravnopravnom (asimetričnom) statusu sagovornika, jer intervjuer ima potpunu kontrolu u diskursu. Teme o kojima se razgovara su aktuelne i interesantne za javnost."

Pošto intervju predstavlja specifičnu formu institucionalnog diskursa, podrazumeva se da podleže izvesnim normama koje se nameću u svakom vidu institucionalizovanih diskursa. Heritage i Clayman (2010: 215-216) su

1 Detaljnije o konfrontacionom intervjuu videti Nikolić 2017. 
detaljno odredili osnovne norme klasičnog intervjua kojih se učesnici u intervjuu moraju pridržavati, kako voditelj - intervjuer (u daljem tekstu IR, prema engleskom interviewer) tako i gost - intervjuisana osoba (u daljem tekstu IE, prema engleskom interviewee). Te norme se svode na opštu strukturu interakcije u kojoj dominira shema pitanje - odgovor, pri čemu IR postavlja pitanja, a IE na njih odgovara; IR određuje ko i kad preuzima reč, koliko dugo sagovornik može da govori, i slično; postojanje publike - što povlači za sobom zahtev da se interakcija organizuje kao ,razgovor za slušaoce“", tako da publika nema osećaj da prisustvuje privatnom razgovoru, već da se taj razgovor vodi baš zbog nje; i u idealnom slučaju, IR je „neutralan“ - ne iskazuje svoje mišljenje, niti mišljenje neke društvene grupe (recimo, svoje medijske kuće). Stoga, formalno, IR samo postavlja pitanja (sam pojam pitanja je veoma širok i obuhva čitav niz mogućnosti), a IE čeka da IR završi, odnosno da čuje celo pitanje na koje treba da odgovori; IE odgovara na pitanje, i taj odgovor je po pravilu elaboriran; IR čeka da IE završi svoj odgovor, pa zatim postavlja sledeće pitanje.

Učesnici u dijalogu treba da se pridržavaju i normi po pitanju sadržine intervjua. Sadržina komunikacije sastoji se u izboru teme ili tema o kojima se razgovara. U svakodnevnom razgovornom diskursu, teme nastaju slobodno, svaki učesnik može da povede razgovor o temi koja ga interesuje, kao i da da doprinos svakoj temi o kojoj je reč, da napravi digresiju ili da se vrati na neku temu o kojoj se ranije razgovaralo. U intervjuu je situacija sasvim drugačija. Što se tiče odabira teme ili tema o kojima će biti reč u nekom medijskom intervjuu, jedino IR može da o njima odlučuje. IE se mora povinovati tom izboru i odgovarati na pitanja koja mu IR postavlja. Pošto su ovi intervjui polupripremljeni, IR unapred obaveštava IE o čemu će razgovarati, pa je IE upućen u sadržinu pre samog razgovora. Međutim, konkretna pitanja ostaju mu nepoznata sve dok ih IR ne postavi u toku intevjua. Možemo, dakle, poći od pretpostavke da i po pitanju sadržine, IR ima potpunu kontrolu u diskursu intervjua.

Ovako postavljene norme i pridržavanje normi od strane učesnika u interakciji podrazumevanju dominantnu ulogu IR. Do promena odnosa moći i preuzimanja dominacije, bar na mahove, dolazi tek kad se od normi odstupi. Svako odstupanje od ovih normi podrazumeva neku vrstu konfrontacije. Stoga možemo reći da je narušavanje odnosa moći osnovna karakteristika konfrontacionog intervjua.

Odstupanje od normi može podrazumevati narušavanje bilo formalne bilo sadržinske strukture diskrusa. 


\section{Narušavanje formalne strukture}

Ako bi se učesnici u intervjuu strogo pridržavali normi formalne strukture u razgovoru redovi govorenja bi se smenjivali po shemi pitanje - odgovor - pitanje - odgovor, i tako do kraja intervjua, s tim da se svako pitanje i odgovor sasluša do samog kraja, bez prekidanja. Međutim, u konfrontacionom intervjuu to nikada nije slučaj, jer tokom ovakve interakcije često dolazi do prekidanja sagovornika. Korpus koji je analiziran u ovom radu sastoji se od po 15 sati ragovora na engleskom (Hardtalk, BBC) i 15 sati na srpskom (10 sati Poligrafa, B92 i 5 sati Pressinga, N1). Da bismo bliže prikazali kakav je odnos broja replika (redova govorenja) i broja prekidanja urađena je statistička analiza celokupnih korpusa.

$\mathrm{U}$ korpusu na engleskom jeziku, ukupan broj prekidanja u toku pojedinačnih intervjua se razlikuje. U nekim emisijama ukupan broj prekidanja je neznatan (11), međutim, i broj takvih inervjua je daleko manji od onih sa velikim brojem prekidanja. U većini intervjua broj prekidanja je oko 30. Ima i intervjua sa izuzetno velikim brojem prekidanja, čak 72, što u velikoj meri čini formalnu strukturu razgovora bitnim činiocem u određivanju odnosa moći u razgovoru, naročito ako broj prekidanja uporedimo sa ukupnim brojem redova govorenja u celom intervjuu. Da bismo prikazali učestalost prekidanja, uporedili smo broj ukupnih redova govorenja u korpusu sa brojem redova preuzetih nakon što je jedan sagovornik prekinuo drugog i preuzeo reč. Ukupan broj prekidanja u engleskom korpusu je 1398 od ukupno 3626 redova govorenja. Odnos između njih u procentima iznosi $38,5 \%$, što znači da se u više od trećine slučajeva reč preuzima prekidanjem sagovornika. Od toga IR prekida sagovornika 840 put što je 60,1\% od ukupnih prekidanja u korpusu, a IE 558 puta, odnosno 39,9\%.

Kao i u engleskom, u korpusu na srpskom jeziku ukupan broj prekidanja u toku pojedinačnih intervjua se razlikuje. Taj broj se kreće od 18 pa sve do $97^{2}$. Ukupan broj prekidanja u srpskom korpusu je 1648 od ukupno 3276 redova govorenja. Odnos između njih u procentima iznosi čak 50,3\%, što znači da se u više pola slučajeva reč preuzima prekidanjem sagovornika. Od toga IR prekida sagovornika 877 put što je 53,2\% od ukupnih prekidanja u korpusu, a IE 771 puta, odnosno 46,8\%.

2 Ovd e treba uzeti u obzir vreme trajanja intervjua. Hardtalk traje oko $25 \mathrm{~min}$, Poligraf oko 30, a Pressing oko 50 minuta. Otud i razlika u najmanjem i najvećem broju prekidanja u engleskom i srpskom korpusu. 
Kad uporedimo dva korpusa vidimo da procentualno u emisijama na srpskom jeziku sagovornici češće preuzimaju red govorenja prekidanjem sagovornika nego u emisjama na engleskom jeziku. Osim toga, ako uporedimo odnos između broja prekidanja i ukupnog broja preuzimanja redova govorenja u celokupnom korpusu na engleskom i srpskom jeziku, videćemo da je taj odnos u engleskom 38,5\% a u srpskom čak 50,3\%. Iz ovoga možemo zaključiti da je konfrontacija, kada je reč o formalnoj strukturi dijaloga, prisutnija u srpskom nego u engleskom dikursu. Osim toga ova dva korpusa se razlikuju i po tome ko koga češće prekida. U engleskom korpusu IR prekida sagovornika mnogo češće nego IE, odnosno 60,1\%, naspram 39,9\% koliko prekida IE, dok je u srpskom korpusu situacija nešto ujednačenija. IR prekida u 53,2\% slučajeva a IE u 46,8\%. Međutim, interesantno je primetiti da se broj prekidanja gotovo ne razlikuje u korpusima kada IR prekida svog sagovornika (840 u engleskom naspram 877 u srpskom). Ono što pravi razliku je broj prekidanja u diskursu od strane intervjuisanih sagovornika (558 u engleskom naspram 771 u srpskom korpusu) što ukazuje na podatak da su, po ovom kriteriju, intervjuisani u srpskim emisijama skloniji konfrontaciji nego u engleskim.

\section{Funkcije prekidanja sagovornika}

Kada govorimo o formalnoj kontroli govornog diskursa, osim manje ili više eksplicitnih verbalnih postupaka, npr: Izvini što te prekidam, postoje postoje i drugi, paralingvistički signali poput pauza, oklevanja, preklapanja replika sagovornika, pa i neverbalnih, koji imaju značajnu ulogu u smenjivanju govornika u dijalogu. Osnovno pravilo u razgovornom jeziku, da jedan govornik govori u datom trenutku, može biti narušeno, što se u svakodnevnom razgovoru odvija na jedan način, dok se u institucionalnim dijalozima uređuje često posebnim pravilima. Tako, na primer, u sudu je strogo utvrđena dominacija sudije u određivanju kad neko može da uzme reč, a u nekim drugim slučajevima, na primer u razgovoru lekara s pacijentom, iako lekar ima dominantnu ulogu, ipak dolazi do narušavanja tako određenih statusnih uloga. Drugim rečima, iako institucionalni razgovor podrazumeva određene uloge koje se socijalno i statusno mogu odrediti kao nadređene i podređene, postoji niz varijacija u odlučivanju kada ko preuzima reč, što samo po sebi zahteva da se svaki pojedinačni tip razgovora mora analizirati i s obzirom na odgovarajući situacioni kontekst. 
U konfrontacionom intervjuu, govornici se često služe prekidanjem sagovornika, bilo da ono započinje upadanjem u reč i prekidanjem, ili preklapanjem, tj. govorenjem $\mathrm{u}$ isto vreme. Iako je razlika između preklapanja dveju replika i prekidanja nekada nejasna, u većini slučajeva sam kontekst razgovora pomaže da se utvrdi da li se radi o pokušaju preuzimanja kontrole u konverzaciji ili o nečem drugom (kao što su, na primer, slaganje sa sagovornikom, delimično slaganje, prividno slaganje i suprotstavljanje ${ }^{3}$ ). Videli smo da i IR i IE često prekidaju sagovornika da bi preuzeli kontrolu u diskursu, ali kada IR preuzima kontrolu dolazi zapravo do ponovnog uspostavljanja normativnog ponašanja. U ovom delu rada interesuju nas samo slučajevi kada IE preuzima kontrolu, jer se samo tada narušavaju pretpostavljeni odnosi moći. Pogledaćemo primere kada se IE suprotstavlja i preuzima kontrolu u diskursu.

U prva dva primera, vidimo kako se suprotstavljanje intervjuisanog ostvaruje prekidanjem, a to prekidanje je vezano za termin ili izraz koji je voditelj intervjua upotrebio, a sa kojim intervjuisani nikako ne želi da se složi:

Primer 1: IR (Stephen Sackur), IE (Richard Lambert, generalni direktor Konfederacije britanske industrije):

IR: And that is a hope, but to come back to the analysts who purport to know most about what's going on and what to look for. The IMF for example have just shaved down their growth prospects for the UK. 2010 - they now say that they'll see growth of just $1 \%$ and a tiny bit more and in 2011 they say it may just be $2 \%$. Now the Government not so long ago was predicting over 3 per [cent...

IE:

[Not this Government, not this Government, but THE Government. $\{\text { nastavlja da govori }\}^{4}$

$(\mathrm{E} 25,2: 45)$

Vidimo da je sintagma the Government, koju IR upotrebljava uz adverbe now $i$ not so long ago, izazvala intervuisanog da prekine sagovornika, kako bi precizirao potencijalnu implikaciju da se radi o ,sadašnjoj vladi“, što on želi da negira, te ističe da se radi o „tadašnjoj“ vladi. Njegove

$3 \quad$ Više o funkcijama prekidanja u Nikolić 2015.

$4 \quad$ Uglastom zagradom kao i njenom grafičkom pozicijom u primerima pokazujemo kada počinje prekidanje. 
reči kojima prekida sagovornika upućuju da se analysts može odnositi na druge (IMF i the Government u značenju ,tadašnje“ vlade), ali nikako na sadašnju vladu, iz čega se može videti i da se on oseća pripadnikom i sledbenikom trenutne vlasti. Na taj način on preuzima reč i kontrolu nad navedenim segmentom intervjua.

Sličan primer nalazimo i u srpskom primeru:

\section{Primer 2: IR (Antonela Riha), IE (Aleksandar Vučić)}

IE: $\quad\{$ izostavljenpočetakreda $\}$ Ali da kažem koje su to mere, da ne bi ljudi rekli: „Došli ste da pričate i da kritikujete samo.“"Dakle

IR:

IE:

[Dosad ste samo to otprilike radili [ali, ali...

[Ne, nismo. Mi smo iznosili naša rešenja ali na konferencije za novinare posvećene ekonomskom napretku Srbije, verovali ili ne, ili nam mali broj novinara dođe ili gotovo niko ne želi da objavi.

$(\mathrm{S} 20,4: 44)$

Na prekidanje od strane voditeljke, u kome se ona, parafrazom citirane kritike u prethodnoj replici (pričate i kritikujete samo - to otprilike $i$ radili) stranke kojoj pripada intervjuisani, izaziva negativnu rekaciju i prekidanje od strane intervjuisanog, koji sada negira dvostrukom negacijom: Ne, nismo., a potom nastavlja da opovrgava da njegova stranka ,samo priča i kritikuje“", naprotiv, oni imaju mere, rešenja u vezi s ekonomskim napretkom Srbije, i sada, a i ranije, samo ih niko nije slušao. Iako se u ovom segmentu vidi „upadica“, prekidanje intervjuisanog od strane voditeljke, i to kritičkom opaskom, koju je intervjuisani samo delimično saslušao i odmah kada je razumeo iskaz, prekinuo ga, poslednja navedena replika jasno pokazuje da je IE preuzeo kontrolu nad tim segmentom razgovora.

Drugi tipični slučajevi su kada se IE pobuni što ga voditelj prekida, i eksplicitno zatraži da ga voditelj ne prekida ili da mu dopusti da završi svoju repliku. To se dešava naročito ako je IR agresivan i prekida intervjuisanog iako je ovaj jasno pokazao da želi da nastavi svoju repliku, ili prekida više puta intervjuisanog tako da ovaj ne može da završi odgovor.

Primer 3 pokazuje kako intervuisani signalizira da kreće sa novom podtemom, voditelj ga prekida, te intervuisani zahteva da završi svoju početu repliku. 
Primer 3: IR (StephenSackur), IE (Christopher Hill, ambasador SAD u Bagdadu) (Prethodno pitanje je bilo šta IE misli o kredibilitetu iračkog premijera pošto se sumnja da je znao za nedavno otkriveni tajni zatvor Muthana, u kojima su zatvorenici mučeni i držani u nehumanim uslovima).

IE: First of all, the issue of Muthanna as soon as we found out about it, we found out about it actually at the time the human rights minister found out about it, and she went to the to the Prime Minister and he shut it down. So it's actually an example of the system working. [Now if you're asking me,

IR: [Let me ask you one [question...

IE: $\quad[\mathrm{Oh}$, oh, oh! Let me finish my thought here because if you're asking me what do I think of torture $\{$ nastavlja da govori\}

Slično kao u primeru 2, IE signalizira i partikulom now i dalje uvodeći novu temu uslovnom rečenicom koja realno implicira novu podtemu (ifyou're asking me), ali ga IR prekida, te on pri samom kraju pokušaja voditelja da ga prekine, uz uzvike (Oh, oh, oh!) eksplicitno traži da nastavi: Let me finishmy thought i potom, kao što je tipično za nastavljanje posle prekida, ponavlja i deo koji je ostao nezavršen: if you're asking me. I potom uvodi svoju podtemu.

Istim rečima, samo na srpskom, traži intervjuisani od voditelja da ga ovaj ne prekida u sledećem primeru:

Primer 4: IR (Jugoslav Ćosić), IE (Predrag Ejdus, upravnik Narodnog pozorišta)

IE: $\quad$ početak izostavljen\} Dakle, praksa je dugogodišnja svih beogradskih pozorišta da omogućavaju mladim studentima, dakle studentima završnih godina, da se pojave na njihovim [scenama.

IR: [A jeste pomislili da da neko može da Vas [upita...

IE: [Sačekajte samo da završim. [Naravno $\{$ nerazumljivo $\}$

IR: [To su Vaši studenti [privatne akademije.

IE: [Dozvolite, molim Vas. To ne samo da mi je da je to slučaj ove godine. \{nastavlja da govori\} 
U ovom slučaju voditelj verovatno zbog signala ,zaključivanja“ putem konektora dakle, kao i uopštavajućeg zaključka: „praksa... svih beogradskih pozorišta" pretpostavlja da je trenutak njegovog preuzimanja reči, međutim IE ga prekida eksplicitnim signalom da nije završio: Sačekajte samo da završim. Međutim, voditelj je uporan i završava svoje provokativno pitanje, te IE još jednom traži da nastavi, s tim što početak, odnosno prva naredna rečenica sadrži samoispravku (To ne samo da mi je . da je to...). Nakon toga, IR više ne prekida IE, već mu dozvoljava da završi svoj red govorenja.

Naravno, moguće su i manje eksplicitne formulacije za zadržavanje kontrole od strane IE. U primeru 5, IE implicira da ga voditelj ne sluša, te nakon takve primedbe uspeva da povrati kontrolu nad sadržajem i dovrši svoju temu.

Primer 5: IR (Stephen Sackur), IE (Frank Field, laburistički poslanik u parlamentu)

IE: It's separate from time limiting, and that's another way of doing it. All I'm saying is that it will be a specific job which will be suitable for you to do and if you don't take it then benefit is stopped. "You've got to get real." I'm [erm

IR:

[So, when people in some of the North of England's industrialized cities where frankly there are dozens of people competing for every single job you say: ["People have got to get real."

IE: $\quad$ [But you're not... you're not...

IR: [You'll be nothing short of insulting!

IE: $\quad$ you're not...Erm they... They fortunately unlike you would be listening to what I'm saying. \{nastavlja da govori\}

$(\mathrm{E} 22,17: 21)$

Ovaj duhovit ali efikasan način da se zadrži kontrola u razgovoru nastaje posle niza prekidanja (prekida prethodna četiri reda govorenja IE), $\mathrm{s}$ tim što je uspešno povezao svoje replike - u prvoj navedenoj replici navodi svoje reči "You've got to get real." Upućene nezaposlenima koji primaju socijalnu pomoć, i poredi potom voditelja sa nezaposlenima koji bi ga sasluišali, dok voditelj to ne čini. Posle ovog komentara IR dozvoljava IE da govori bez prekidanja sve dok ne završi šta je želeo da kaže. 


\section{Preuzimanje kontrole nad sadržinom}

Kontrolu nad sadržinom IR ima po pravilu tokom celog trajanja intervjua. Ona se prvenstveno sastoji od izbora teme ili tema za razgovor koje IR uglavnom unapred priprema, ali i vođenja razgovora. Tokom intervjua IR temu prvo uvodi, zatim je menja i prelazi na drugu, ali mora ponekad da insistira da se razgovor nastavi o nekoj temi koju IE pokuša da izbegne ili promeni, zatim može da odloži temu za kasnije ili da se na neku raniju temu vrati. U klasičnom intervjuu ova norma se poštuje uglavnom bez izuzetka, ali u konfrontacionom intervjuu IE često pokušava da preuzme kontrolu nad sadržinom, jer u ovakvom tipu intervjua pitanja koja IR postavlja su uvek provokativna i u velikom broju slučajeva stavljaju IE u nezgodan položaj jer baš na takva pitanja, koja su po pravilu delikatna, IE ne želi ili ne sme da odgovori, a baš na njih javnost (voditelj u ime javnosti) želi da dobije odgovore.

Pogledajmo primere u kojima IE narušava odnose moći po pitanju kontrole sadržine u diskursu. Iz korpusa na engleskom jeziku navodimo sledeći primer za promenu teme: IE (Noam Chomsky) preuzima kontrolu kada usred svog odgovora na pitanje o izjavi Bin Ladena da je unapred izračunao broj žrtava napada na Svetski trgovinski centar, izgovara sledeću rečenicu (u italiku):

\section{Primer 6: IE (Tim Sebastian), IE (Noam Chomsky)}

IR: Because he calculated in advance the number of casualties from the enemy who'd be killed based on the position [of the tower...

IE: [Which means that he took credit for it several months later. If someone takes credit for something several months later, that does not authorize an attack before evidence is presented. Look, this entire discussion is irrelevant. If the United States wanted to observe international law, there was a very easy way to do it, namely, go to the Security Council, get a resolution authorizing the use of force, which it certainly could have done.

(E1a, 2:27)

Posle razmene niza opaski o tome da li je američko bombardovanje Avganistana posle terorističkog napada na kule bliznakinje u Njujorku bilo po zakonu ili nije, pri čemu IR navodi razloge koji bi mogli opravdati to bombardovanje, a IE ih jedan po jedan odbacije, IE proglašava diskusiju 
irelevantnom. Samim tim, on praktično kaže da je i trenutna rasprava o datoj temi irelevantna. IE se poziva na međunarodni zakon po kojem se za svaki napad na stranu zemlju mora dobiti odobrenje Saveta bezbednosti, što SAD nisu uradile, pa je stoga, po njemu, cela diskusija o drugim razlozima irelevantna.

Iako IR nastavlja da postavlja pitanja u vezi sa ovom temom, ono što je IE ovde izgovorio kao i način na koji je to obrazložio, uz još nekoliko preuzimanja kontrole tokom ovog dela intervjua, sigurno je ostavilo jak utisak na publiku koja ne mora da zna koje korake mora jedna zemlja da preduzme da bi napala drugu, a koja je bombardovanje Avganistana smatrala za logičan odgovor na teroristički akt od 11.09.2001.

Ovaj deo razgovora se završava potpunim preuzimanjem kontrole sadržine od strane intervjisanog u sledećem odlomku:

Primer 7: IE (Tim Sebastian), IE (Noam Chomsky)

IE: If you think you know... Suppose the British discovered - as they have, in fact - that that some of the people involved in IRA bombing are in the United States and they've called for extradition of those people, the US has refused. Do they then have the right to bomb the United States?

IR: (...) You think they're... No, of course not.

IE: Well, fine. Then you don't think that the United States has the right to bomb Afghanistan. 'Cause it's the same thing.

IR: Professor Chomsky, in your book...

Promena sadržine ogleda se u uspostavljanju nove podteme koja je bitna za celokupnu debatu između voditelja i intervjuisanog. Naime, IE uvodi temu analognog slučaja koji po mišljenju intervjuisanog potvrđuje njegovu osnovnu tezu - da bombardovanje Avganistana nije imalo odgovarajuću zakonsku osnovu. Ustvari, ono što je posebno interesantno u ovom primeru konfrontacionog intervjua je činjenica da se analoško vezivanje podtema, inače značajno i u svakodnevnom razgovoru (Polovina, 1987: 110-114), u kome se analogija koristi pre svega u cilju potvrde solidarnosti među sagovornicima, ali i u konfrontacionim diskursima (Eemeren, 2007) u kojima, pak, sagovornici koriste analogiju u dokazivanju suprotstavljenih stavova u vezi sa jednom opštom temom, sistematski provlači kroz ceo intervju. Ovakvo analoško vezivanje podtema 
za osnovnu temu naročito često koristi IE (on poredi slučaj bombardovanja Avganistana sa nekoliko drugih konfliktnih situacija u svetu), što IR u nekoliko navrata prihvata kao tip argumentacije, ali ponekad i reaguje na poređenja s čuđenjem (IE: I'm puzzled by your comparisons, Bin Laden is comparable to Brzezinski?), te u sadržinskom smislu IE preuzima kontrolu do te mere da IR ponekad ostaje bez reči, što je retkost u intervjuu, a kamoli u konfrontacionom intevjuu koji uvek vode iskusni, profesionalni voditelji koje se bave uglavnom samo takvim vidom medijske komunikacije. Ovde možemo dodati da je posledica ovog preuzimanja kontrole dvojaka: (1) IE ima poslednju reč po pitanju jedne teme u intervjuu i (2) IR je prinuđen da promeni temu. Iz ovog primera možemo takođe zaključiti da asimetrična kontrola u konfrontacionom diskursu ne znači da je IR uvek dominantni učesnik u diskursu.

Dok je u prethodnom primeru na engleskom jeziku dosledno nastojanje da se replike vezuju za osnovnu temu, iz srpskog korpusa navešćemo jedan duži odlomak koji pokazuje da gotovo asocijativno vezivanje za prethodnu temu, a ono je karakterističnije za manje čvrstu organizaciju svakodnovnog razgovornog jezika (Polovina, 1987, 110-114), može da posluži za preuzimanje kontrole i u ovom tipu intervjua. Opšta tema ovog intervju je „korupcija”.

Primer 8: IR (Jugoslav Ćosić),IE (Čeda Jovanović)

IR: Ali hajde da Vas pitam za ovu izjavu koja nije baš mnogo pažnje izazvala, a u suštini predstavlja jednu vrstu indirektne optužbe ili sumnje, da tako kažem, najblaže reči za korupciju, Vi ste sugerisali novinarima da da provere ko je bio gost ruskog fudbalskog kluba Zenit na Super kupu Evrope u Montekarlu nedavno.

IE : Da, bio je Ivica Dačić.

IR: Kakav to značaj ima u kontekstu ove priče?

IE : Ja mislim da ima, pošto je generalni sponzor tog kluba predsednik Gazproma Medvedev, (... ) ne Dmitri koji je predsednik Rusije, nego drugi Medvedev.

IR: Dobro, to još ne govori ništa o korupciji, mislim, Vi sad Vi stavljate u kontekst, jedan kontekst koji ima svoju poruku, gospodine Jovanoviću, ali kad tako nešto kažete onda je jasno na šta mislite i šta zapravo hoćete da kažete. Jeste spremni da to kažete javno? Da to kažete: „Da, ja sumnjam da [postoji korupcija koja je vezana za tog i tog čoveka.“

IE : [Ja se nadam... Ja se nadam... Ja se nadam da još uvek nisu prekinuli program vaše televizije, mislim, još nisu došli novi vlasnici NIS-a, kada dođu onda će možda moći to da rade, pošto Gasprom po ruskom zakonu ima pravo na svoje oružane snage, pa ne znam [da li će to moći.... 
IR: [Dobro nema po srpskom zakonu.

IE : Ali su izuzeti iz srpskih zakona i za to su se postarali naši pregovarači [koji su...

IR:

način su izuzeti iz srpskih zakona?

[Na koji način? Na koji

$[\ldots .$.

IE : [Pa nema nikakve veze sa ekologijom garancija naše države da će biti prekinuti svi sudski procesi koji se vode protiv Naftne industrije Srbije, i garancija naše države da se neće ništa desiti sa tužbama koje su pokrenute.

IR: Dobro, hajde da Vas vratim samo na ovo pitanje od malopre.

$(\mathrm{S} 1,10: 30)$

Tek kada se čitav ovaj deo pogleda u celini, može se zaključiti da postoji asocijativna veza između korumpiranosti i veze domaćeg političara i ruskog vlasnika velike kompanije, i neku vrstu implikature izvodi sam IR: Vi sad Vi stavljate u kontekst, jedan kontekst koji ima svoju poruku, gospodine Jovanoviću, ali kad tako nešto kažete onda je jasno na šta mislite $i$ šta zapravo hoćete da kažete, ali IE (Čedomir Jovanović) uvodi novu temu o ,izuzeću ruske firme Gasprom iz srpskih zakona“. IR prihvata i razgovor se vodi o temi koju je uveo IE. Tek kad IE potpuno preuzme kontrolu navođenjem još nekih elemenata ugovora koji sve više udaljavaju razgovor od IR teme, IR vraća IE na prvo pitanje.

Dok su u prethodna dva primera ilustrovane promene tema od strane IE, u narednim primerima ilustrovaćemo kako intervjisani uspevaju da se izbore za nastavljanje teme uz traženje dozvole uprkos naporima voditelja da promene temu. Razgovor se vodi o opstanku britanskih preduzeća u finansijskoj krizi.

Primer 9: IR (Stephen Sackur), IE (Richard Lambert)

IE: Here's a couple of things: one is, it's rather strange but true that the level of company bankruptcies now is far lower than it was in the early 90s. There's far fewer companies going bust right now than had been in past episodes in cycles like that. I mean I think the other thing one has to think of is that, you know, business investment is at a low level, should recover and er we hope that it will.

IR: Now, let let's just talk [now...

IE: $\quad[\{$ nerazumljivo $\}$ If I could just add one more thought. It's that what business has the strongest interest in is economic stability. What businesses want is a world in which they can see that inflation is un- 
der control, interest rates are low and stable and that they're not gonna get whacked with tax increases or shock changes [in the...

IR: [Sure, but they also, [they...

IE: $\quad$ [and and and what they're worried about now, what they would be worried about now would be if we went on what is the biggest fiscal deficit in the G20, the biggest and the most steep decline in fiscal conditions in the G20, then we would be looking forward to a world which was not gonna be stable. The best hope of stability is to get the public finances back into shape.

IR: Right, let's talk then about...

$(\mathrm{E} 25,5: 23)$

Posle prvog prikazanog reda govorenja intervjuisanog ukazuje se mogućnost voditelju da preuzme reč, što on i pokušava, ali IE traži dozvolu da doda još jednu misao. U takvim slučajevima IR retko odbija molbu. Kada IR drugi put pokuša da preuzme reč, ovoga puta vezano za temu o kojoj je reč, IE nastavlja da govori sve dok ne završi misao. Tek tada IR menja temu.

Sličan je i sledeći primer na srpskom jeziku.

Primer 10: IR (Jugoslav Ćosić), IE (Predrag Ejdus)

IE: Apsolutno sam si... Ako to je nešto što interesuje vas i javnost, a ja ću reći javnosti: „Da, moguće je.” Ima ljudi kojima je i tri naslova mnogo da igraju. Ja igram 15 naslova. Ja igram između 15 i 20 predstava. To ne znači da ih ja sve igram fantastično dobro itd., ali ja tako radim već 30 godina.

IR: U redu, pitao sam Vas, mislim da...

IE: $\quad$ Ali ja bih samo još nešto [rekao.

IR: $\quad[\mathrm{Da}$, izvolite.

IE: Izvinjavam se. Ovaj, pitanje organizacije vremena, organizacije posla. Niste me pitali kako ja to postižem. Da, postižem tako što ustanem u šest ujutro i radim do jedan sat noću, svakog dana. Vi ćete reći: „Vi ste ludi, za koje pare [Vi to radite?"

IR: me je zanimalo [kako uspevate?

[Ne, neću, neću, samo samo

IE: [Ali, ja vam to kažem, ja to radim tako već godinama.

IR: U redu, gospodine Ejdus, ono što što je činjenica jeste da se svi ovi problemi najmanje osećaju na na sceni Narodnog pozorišta...

Kao i u engleskom primeru (If I could just add...), IE traži dozvolu da nastavi da govori (ja bih samo još nešto rekao). Ovu strategiju traženja 
dozvole Clayman i Heritage (2002: 258) nazivaju deference ${ }^{5}$ to the IR. Oni razlikuju dva načina na koje se to može izvesti. Prvi je prikazan u prethodnim primerima gde IE upućuje molbu za dozvolu (If I could just add, odnosno ja bih samo još nešto rekao). Drugi način podrazumeva zahtev IE da mu se dozvoli da nešto kaže.

U naredna dva primera nastavljanje opšte teme uvođenjem novih podtema ostvaruje se bez traženja dozvole, ali sa eksplicitnim indikacijama, odnosno najavljivanjem novih podtema, i to ne na samom početku replike, već unutarreplički. Dakle, radi se o otpočinjanju teme kada je već red govorenja preuzet, što IE koristi da uvede novu temu.

\section{Primer11: IR (Stephen Sackur), IE (Jeffrey Sachs)}

IR: And just to be clear on this point of global governance, cause that's where I want to take our conversation, are you acknowledging to me that there is no way that this idea can fly unless you get sign-off on it from all of the major economies. I'm thinking: the US, the Europeans, Japan, China as well and India. I mean, everybody has to be involved in this or it can't possibly work. True?

IE: I wouldn't say that, and I want to clarify you a couple of things. One idea might be to have an international tax authority. That's not the idea here. I don't think that that has a chance in the world, certainly my country was born in a tax rebellion. The idea of an international tax would be another revolution. So, that's not gonna happen. The idea here is that there's national tax collection, country by country, but that [there's coordination

IR:

IE: It's not gonna be identical \{nastavlja da govori\}

[But on the same basis.

$(\mathrm{E} 4,11: 44)$

IR dozvoljva IE da ne odgovori eksplicitno na njegovo opšte pitanje (True?), već dozvoljava IE da elaborira na svoj način. Čak ga i ohrabruje u sledećem redu govorenja (But on the same basis.), da bi IE posle toga nastavio da govori. Za razliku od prethodnih primera u kojima IE traži dozvolu da nešto doda, u ovom primeru IE upotrebljava glagol iskaz I want to clarify things kojim izražava zahtevi najavljuje da će promeniti temu.

Isti je slučaj i u srpskom primeru:

5 Deference prevodimo kao poštovanje, ali treba napomenuti da ona podrazumeva pokornost. 


\section{Primer 12: IE (Vida Petrović-Škero), IR (Jugoslav Ćosić)}

IE: $\quad$ izostavljen početak\} kada govorimo o kaznenoj politici možemo da razgovaramo, ali ću reći da će građanima uvek da se učini da je godinu dana možda mala kazna. [Učiniće se...

IR:

700 mrtvih je bilo prošle godine

[Pa zar ne,

IE: I...

IR: u saobraćajnim [nesrećama u Srbiji. 700.

IE: $\quad$ [Naravno, onda ćemo reći možda. Ali...

IR: [Je l' treba da budemo pravnici i eksperti za to?

IE: [mi ne znamo zašto i zato postoji drugostepeni sud koji će ocenjivati ovakvu vrstu kazne i on će znati činjenice i znaće pravo. Ali (...) ću nešto drugo reći u pogledu ovoga što ste izgovorili. (...) Ja neću reći da su sudovi sjajni u izricanju kazne. \{nastavlja da govori\}

I ovde najava promene teme dolazi ne na samom početku replike, već unutar nje, što takođe podrazumeva da govornik oseća da „vlada” razgovorom u tom trenutku. I u engleskom i u srpskom primeru vidimo da IE nastavljaju da govore, a da ih IR ne prekida.

Iako sličan primeru 1, po tome što sagovornici vezuju svoje replike dosledno upotrebljavajući isti termin sukcesivno, ali jedan u slučaju voditelja, drugi u slučaju intervjuisanog, naredni primer ilustruje kako se u replici za replikom javlja isti postupak intervjuisanog kojim se izbegava odgovor na ponovljena pitanja o istoj temi i to tako što se svaki put ponavlja u odgovoru naizgled blizak termin, tj. slična tema, ali koja nikako nije konkretno povezana sa pitanjima voditelja.

\section{Primer 13: IR (Stephen Sackur), IE (Jens Stoltenberg)}

IR: You have 28 members, you have one dominant member, that is the United States of America. The United States of America now has a president who, just a few days ago, declared NATO "obsolete".

IE: NATO is the most successful alliance in history, because we have been able to adapt to change. For 40 years we did collective defence in Europe, deterring Russia. Then we adapted after the end of the Cold War and we projected stability beyond our borders and in conflicts in Balkans, Kosovo, Bosnia, fighting terrorism in Afghanistan and we are adapting again, responding to a more assertive Russia in the east.

IR: How do you adapt to a US president who believes NATO to be obsolete?

IE: What I will tell him and actually I I already told him is that NATO is chang- 
ing because the world is changing. When I spoke to him, he was very committed to NATO and he expressed a strong support to NATO. So, I actually look forward to working with him in continuing to adapt to NATO because I don't see any contradiction between saying that NATO is important but at the same time saying that NATO has to change, [NATO has to adapt...

IR:

[I understand, but let's engage with what he has actually said to the Times newspaper just a few days ago he said that in his view NATO had become obsolete. I'm just wondering how you reacted to that.

IE: Well, I will continue to tell the story about NATO, an alliance which has proven, for almost 70 years, able to [change when the world is changing...

IR:

[Sure... I I I

IE: $\quad$ Then I will sit down with him and discuss concrete measures, concrete issues where we can do more, where we can change more. And then I agree with President Trump that NATO has to modernise. That is exactly what we have started to do. And we are doing that by addressing issues like defence spending and terrorism, the two main issues he has mentioned.

$(\mathrm{E} 28,1: 25)$

Kao što se vidi iz reči koje smo istakli, dok IR insistira na leksemi kojom je NATO označen kao „zastareo” (obsolete), u svakom odgovoru intervjuisanog izbegava se negacija takve karakteristike, a time i odbijanjen da se o "zastarelosti" govori. U svakom od odgovora, IE upotrebljava druge glagole: change, adapt, modernize, koji daju pozitivnu karakterizaciju njegove organizacije, i u krajnjoj liniji impliciraju da ta organizacija nije obsolete, a što je još važnije, ovakav izbor leksike mu omogućava da se verbalno ne suprotstavlja rečima predsednika Trampa, već se na pozitivnim aspektima "modernizacije" s njim može dogovarati i pregovarati. Pred kraj niza replika, IE gotovo sasvim otvoreno priznaje da se neće povinovati zahtevu voditelja da odgovori konkretno o tome što je Tramp rekao da je „NATO zastarela organizacija”, već će nastaviti „svoju priču”: -Well, I will continue to tell the story about NATO., i time uporno odbacuje sadržinu koju voditelj pokušava da mu nametne. 


\section{Zaključak}

Naša analiza pokazuje daneke od pretpostavki o formalnoj i sadržinskoj strani intervjua, a pogotovo konfrontacionih intervjua u medijima, kao što su uobičajeni redosled uzimanja reči i smenjivanja govornika ili dominacija novinara - intervjuera, kako u formalno organizacionom aspektu te komunikacije, tako i u sadržinskom, moraju biti modifikovane. Naime, intervjuisani ima na raspolaganju niz diskursnih i jezičkih sredstava kojima može da ,nadvlada“ intervjuera. Nekada to ostvaruje eksplicitnim zahtevom da bude saslušan, da mu se dopusti da završi svoj govor, misao, a nekada to čini implicitnim putem, manje ili više učtivo. Konfontacioni intervju, po svojoj prirodi, odnosno po ciljevima koje imaju sagovornici, može se okarakterisati i kao debata suprotstavljenih sagovornika, jer, iako je voditelj, tj. intervjuer u institucionalnom smislu idealno neutralan, a razgovor vodi radi publike, njegovo nastojanje da dođe do pravih informacija, do činjenica, i sl., čini da se pojavljuje kao sagovornik suprotstavljenog mišljenja. U takvoj situaciji dolazi do čestih međusobnih prekidanja i upadica kod oba sagovornika, kod nekih više, kod drugih manje. Moguće je da do razlike, u pogledu prekidanja, između intervjua na engleskom i srpskom dolazi iz kulturoloških razloga, ali faktori koji na to utiču nije jednostavno odrediti, s obzirom da su i sagovornici u ovakvim intervjuimapoznate ličnosti koji imaju socijalni značaj, a time indirektno i određenu socijalnu moć, pa i jaku individualnost. Stoga, recimo, neki sagovornici (primeri 6 i 7, 13) koji učestvuju kao intervjuisani i time se nalaze u ,podređenom“ položaju, dosledno primenjuju „svoje“ strategije kako bi stekli prednost nad voditeljem: davanje analognih primera i poređenja kako bi se argumentovao početni stav, odbijanje da se prihvati odgovor na pitanje postavljeno na način koji ne odgovara intervjuisanom, te tako menjaju tematski pravac koji intervjuer želi da nametne. Intervjuisani imaju načina da ostvare nadmoć u komunikaciji i na druge načine: da „koriguju“ voditelja zbog pogrešnih izraza (primeri 1 i 2 ), da traže eksplicitno traže da ne budu prekidani (primeri 3-5), da menjaju sadržinu toka razgovora analogijom, asocijacijatvno, uopštavanjem teme ili uvođenjem specifičnih tema ili egzemplifikacije uz traženje dozvole za takvu promenu (primeri 9, 10) ili bez (primeri 11 i 12), ili da jednostavno odbijaju nametanje jednog stava koji nudi voditelj (primer 13). Iako se, naravno, mnogi od ovih 
diskursnih i jezičkih strategija (prekidanje, promena teme, eksplicitni ili indirektni metadiskurzivni postupci i sl.) i u drugim tipovima komunikacije javljaju, smatramo da česta nastojanja intervjuisanih da naruše moć intervjuera predstavljaju jedno od bitnih obeležja upravo konfrontacionog intervjua.

\section{Literatura}

Clayman, S. and Heritage, J. (2002). The News Interview.Cambridge: Cambridge University Press.

Dijk van, T. A. (Ed.), Handbook of discourse analysis, vol. 3 (pp. 95-119). New York: Academic Press.

Drew, P. and J. Heritage (Eds.) Talk at Work. Cambridge: Cambridge University Press, 101-134

Eemeren van, F.H., Houtlosser, P. and Snoeck Henkemans, F. (2007). Argumentative indicators in discourse. Dodrecht: Springer.

Fairclough, N. (1995). Media Discourse, London: Edward Arnold.

Fairclough, N. \& Wodak, R. (1997). Critical Discourse Analysis. in T. van Dijk (ed.) Discourse as Social Interaction (pp. 258-284). London: SAGE.

Heritage, J. \& Clayman, S. (2010). Talk in Action. Interactions, identities, and institutions. Chichester: Wiley-Blackwell.

Hutchby, I. and Wooffitt, R. (1998). Conversation Analysis. Cambridge: Polity Press.

Kress, G and Fowler, R. (1979). Interviews. In Fowler, R et al. (eds.), Language and control, 63-80. London: Routledge and Kegan.

Mišić Ilić, Biljana (ur.), Lopičić, Vesna (ur.). Jezik, književnost, diskurs, Jezička istraživanja. Zbornik radova. Niš: Univerzitet u Nišu, Filozofski fakultet.

Nikolić, M. (2015). Metalinguistic means for expressing power in discourse. У: Mišić Ilić, Biljana (ur.), Lopičić, Vesna (ur.). Jezik, književnost, diskurs, Jezička istraživanja. Zbornik radova. Niš: Univerzitet u Nišu, Filozofski fakultet, str. 327-338.

Nikolić, M. (2017). Pokušaj definisanja konfrontacionog intervjua, Анали Филолошкоі факулиетей, Vol. 29, No. 1. стр. 125-148.

Polovina, V. (1987). Leksičko-semantička kohezija u razgovornom jeziku, Beograd, Filološki fakultet.

Schegloff, E. A. (1992). On talk in institutional occasions. In P. Drew and J. Heritage (Eds.) Talk at Work. Cambridge: Cambridge University Press, 101-134.

Wolfson, N. (1976). Speech events and natural speech: some implications for sociolinguistic methodology. Language in Society, 5. (pp 189-209). 
Internet strane

BBC, Hardtalk, zvanična internet strana. Dostupno preko:

http://www.bbc.co.uk/programmes/b006mg2m

http://news.bbc.co.uk/2/hi/programmes/hardtalk/about hardtalk/default.stm

http://www.bbc.co.uk/programmes/n13xtmdc/profiles/stephen-sackur[09.06.2018]

B92, Poligraf, zvanična internet strana.Dostupno preko:

http://www.b92.net/lica/bio.php?nav_id=211661

http://www.b92.net/info/vesti/index.php?yyyy $=2009 \& m m=06 \& d d=19 \& n a v$ category=15\&nav_id=366907[20.12.2017]

N1, Pressing, zvanična internet strana.Dostupno preko:

http://rs.n1info.com/a4557/TV-Emisije/Pressing/Pressing.html[09.06.2018]

Vesna G. Polovina

Melina M. Nikolić

\section{Summary}

\section{SHIFTING POWER RELATIONS IN CONFRONTATIONAL INTERVIEW}

Confrontational interview is a modern form of news interview characterized by conflicting aims that the participants attempt to achieve. Although the interviewer should be neutral due to the institutional setting of the interview and the conversation targets the audience, their insistence to obtain the desired information often leads to confrontation. In this kind of situation mutual interruptions occur frequently. Furthermore, the interviewees are people of consequence, influential in their respective fields of work and, therefore, very often use certain strategies of their own to gain control over the interviewer, thus shifting institutionally preset power relations. The analysis of linguistic means and strategies used in confrontational interviews in English and Serbian to disrupt those standardized power relations shows that some of the existing assumptions about formal and topical control in the interview, such as the usual turn-taking and turn relevance places as well as the domination of the interviewer, should be modified. The interviewees have at their disposal a wide range of various linguistic means and strategies which they more or less successfully apply in the conversation in order to take over control in discourse, thus trying to achieve their own aim of disclosing as little sensitive information as possible while at the same time presenting themselves as fully cooperative and informative.

Key words: confrontational interview, institutional interview, critical discourse analysis, power relations 